\title{
Uma nova geração da teoria crítica
}

Nathalie Bressiani - UFABC

Nos últimos anos, foram publicados na Alemanha diversos textos que, considerados em conjunto, apontam para o surgimento de uma nova geração de teóricos críticos. Embora Jürgen Habermas e Axel Honneth continuem sendo as principais referências para os autores dessa geração, parece ter se consolidado recentemente, principalmente no contexto alemão, a percepção de que eles não teriam conseguido desenvolver um diagnóstico suficientemente complexo das patologias sociais ou uma teoria capaz de criticá-las adequadamente. As consequências normativas de tal afastamento, iniciado já há algum tempo, se evidenciam com maior força agora, momento em que, com o objetivo de dar conta das carências que identificam nas obras desses dois autores, alguns teóricos tentam repensar os fundamentos da crítica social e elaborar, a partir deles, novos modelos de teoria crítica.

Tendo em vista esse novo contexto de discussão e sua importância para os futuros desenvolvimentos da teoria crítica é que optamos por abordar aqui os livros de três autores que, apesar de ainda pouco conhecidos no Brasil, são particularmente importantes no interior dessas discussões. São eles: Crítica como 
práxis social. Autocompreensão social e teoria crítica, de Robin Celikates; Crítica como genealogia. História e teoria do sujeito segundo Nietzsche e Foucault, de Martin Saar; e, Alienação. A atualidade de um problema social filosófico, de Rahel Jaeggi.

Publicados pela mesma editora (Campus Verlag) entre 2005 e 2009, os três livros fazem parte de coleções coordenadas por Axel Honneth: os de Jaeggi e Celikates (2005 e 2009) pertencem ao selo de "sociologia e filosofia social" e o de Saar ao de "teoria e sociedade" (2007). Apesar de abordarem autores e temáticas distintas, os três livros partem de um diagnóstico semelhante: a tese da colonização do mundo da vida não é adequada, e uma teoria crítica da sociedade deve ser capaz de compreender e criticar as relações de poder que se reproduzem no interior das interações sociais. Esse projeto, já defendido por Honneth em Crítica do Poder, constitui o ponto de partida do trabalho desses autores, cuja principal particularidade consiste na defesa de que sua realização exige que o próprio significado da crítica social seja colocado novamente em questão. Passo com o qual eles rompem não só com Habermas, como também com Honneth.

Rejeitada por Jaeggi, Celikates e Saar, a teoria da modernidade desenvolvida por Habermas, principalmente durante a década de 1980, caracteriza-se pelo diagnóstico de que as sociedades modernas resultam de um processo dualista de racionalização social que teria levado ao desacoplamento entre sistema e mundo da vida, a saber, a uma diferenciação entre esferas sociais nas quais as ações seriam sistemicamente coordenadas, a economia e a burocracia, e àquelas nas quais as ações seriam coordenadas comunicativamente, estas responsáveis pela reprodução simbólica do mundo da vida (cultura, socialização e sociedade). Segundo Habermas, esse processo de dupla racionalização, que 
está na base da modernidade, é responsável pela liberação da ação comunicativa das amarras da tradição e teria garantido, além disso, a rapidez e a eficácia necessárias à reprodução material de sociedades complexas, nas quais não seria mais possível coordenar linguisticamente os objetivos econômicos e burocráticos sem sobrecarregar as interações comunicativas (Habermas 1987, pp. 171-293).

Embora frise a importância dos processos de desacoplamento e racionalização para a constituição da modernidade, Habermas não deixa de explicitar suas consequências negativas. De acordo com ele, depois de se diferenciarem, os imperativos sistêmicos que organizam a reprodução material da sociedade passaram a extrapolar o domínio dos subsistemas e a invadir o mundo da vida, substituindo as interações sociais que estão na base de sua reprodução simbólica. Esse alargamento da forma funcionalista de coordenação de objetivos, própria aos sistemas, em direção às esferas que dependem da comunicação possui um caráter reificante e constitui, para Habermas, a causa das patologias sociais. Para ele, portanto, as patologias sociais da modernidade são o resultado de distorções na comunicação provindas de fora, isto é, resultam de sua colonização pelo sistema (Habermas 1987, pp. 489-547). Os processos comunicativos dos quais depende a reprodução simbólica do mundo da vida, em contrapartida, não são apontados como possíveis causas de patologias.

Poucos anos após a publicação de Teoria da Ação Comunicativa, onde Habermas apresenta esse diagnóstico, Honneth afirma que o dualismo social e a tese da colonização do mundo da vida desenvolvidos por ele não dão conta de compreender diversos fenômenos sociais (Honneth 2003, cap. 9). Contrapondo-se a eles, Honneth defende que o desenvolvimento social como um 
todo está atrelado a normas, bem como que as relações de dominação perpassam a interação social, que também produz assimetrias. Tendo isso em vista, Honneth desenvolve uma teoria crítica do reconhecimento por meio da qual procura mostrar que não há esferas sociais não-normativas, nem um âmbito comunicativo isento de relações de poder. Num primeiro momento, contudo, seu foco recai sobre a primeira tarefa. Ele reforça o caráter normativo da sociedade e, ao fazê-lo, acaba relegando a um segundo plano considerações sobre a negatividade social. Apesar de apontar para os limites do diagnóstico de patologias sociais desenvolvido por Habermas, nesse primeiro momento Honneth não mostra como seria possível compreender as distorções nas relações de reconhecimento sem lançar mão de um dualismo.

Consciente dessa negligência, que foi sublinhada por alguns de seus principais críticos (Cf. Owen Brink, 2007; Patherbridge, 2013; Fraser, 2003), Honneth passa a abordá-la em diversos textos da década de 2000, como Reificação ou "Paradoxos da modernização capitalista" (Honneth 2005), nos quais dá diferentes indicações de como os bloqueios à emancipação poderiam ser compreendidos a partir de sua teoria do reconhecimento. Neste último artigo, que possui grande importância para Celikates, Jaeggi e Saar, por exemplo, ele afirma que determinadas normas sociais amplamente aceitas, como a da autonomia e a da independência, foram distorcidas e são hoje utilizadas para promoverem o contrário de seu conteúdo original, no caso, o desmantelamento do Estado de bem-estar social. Ao fazer isso, Honneth começa a esboçar um diagnóstico das patologias sociais na linha do projeto defendido por ele em Crítica do Poder.

Os livros que nos interessam aqui - Crítica como genealogia, Alienação e Crítica como práxis social -, todos escritos e 
publicados no decorrer dessa mesma década de 2000, estão imediatamente inseridos nesse contexto de discussão. Assim como Honneth, seus autores visam desenvolver um diagnóstico que, sem lançar mão de um dualismo, atente para o caráter normativo das patologias sociais. Diferentemente dele, contudo, Saar, Jaeggi e Celikates relacionam os problemas relativos à teoria social e ao diagnóstico de Habermas diretamente ao tipo de crítica mobilizado por ele. Para eles, o diagnóstico de que a interação social está perpassada por assimetrias e as reproduz coloca em questão a possibilidade de que a crítica social seja ancorada na reconstrução da estrutura normativa da própria interação social (Cf. Celikates, 2009, pp. 192-194). A elaboração de um novo diagnóstico não seria, por isso, a única exigência decorrente da recusa do diagnóstico habermasiano. Também seria preciso repensar, de forma mais radical, as bases e o sentido da crítica social. Motivo pelo qual esses autores têm se voltado, novamente, à questão "o que é crítica?" (Wesche Jaeggi, 2009) e abordado a relação entre novos diagnósticos de época e concepções de crítica imanente (Nobre, 2012, p. 24).

De acordo com Martin Saar, aqueles que partem de um diagnóstico dualista podem tomar a própria liberdade como critério para criticar os impedimentos que a bloqueiam, bem como para analisar as causas da manipulação e do poder que os geram. Enquanto é tido como o oposto da liberdade, o poder pode ser criticado como heteronomia ou influência externa. O próprio conceito de poder mobilizado nesse caso permite uma oposição entre práxis autônoma e heterônoma. Aqueles que se filiam a um diagnóstico monista, por outro lado, não têm como assumir essa concepção de crítica. A defesa de que "nenhuma situação pode ser descrita como absolutamente livre de poder e nenhuma 
forma de interação social pode ser entendida como algo que está primariamente fora ou livre da influência do poder" (Saar, 2009, p. 583) faz com que seja mais difícil, para estes autores, explicitar sobre qual práxis sua crítica se ancora. Afinal, se o poder está intrinsecamente vinculado à interação social, ele não pode mais ser entendido como aquilo que a bloqueia. O que faz com que ela também já não possa mais funcionar como padrão da crítica. Para Saar, portanto, a recusa do dualismo exige a formulação de uma nova forma de crítica social. Crítica como genealogia constitui sua tentativa de dar conta dessa exigência.

Retomando, nesse livro, alguns elementos das teorias de Nietzsche e Foucault, Saar procura defender que a noção de genealogia mobilizada por eles tem de estar no centro de uma teoria crítica. Como afirma ele, "esse livro tem o objetivo de reconstruir e defender sistematicamente a ideia e a pretensão de uma crítica genealógica, que procede histórico-geneticamente (Saar, 2005, p. 9). Para Saar, dentre todas as formas possíveis de crítica, a genealógica é a mais adequada ao presente, pois corresponde a "uma análise radical que expõe as raízes históricas de um valor, uma instituição ou uma práxis e direciona o conhecimento sobre a gênese [gewordenheit] desse objeto contra ele mesmo, para comprometê-lo e deslegitimá-lo em função de sua origem" (Ibid, p. 9). Na medida em que explicita a influência do poder no surgimento dos valores, identidades e instituições vigentes, a genealogia permite uma vigorosa crítica social sem ter de postular, para isso, algo que esteja para além do poder. A genealogia constitui, nesse sentido, uma importante ferramenta para os que querem fazer uma crítica social sem se valer de uma estratégia dualista.

Para melhor explicitar os elementos que caracterizam a crítica 
genealógica, Saar divide seu livro em três partes. Na primeira delas, ele argumenta que a noção de genealogia é central para Nietzsche desde aforismos de 1874, até seus escritos posteriores, passando por textos como Genealogia da Moral, onde o autor procura criticar os valores morais vigentes por meio de uma análise de sua gênese. Ao dar centralidade à noção de genealogia, Saar apresenta uma interessante interpretação dos textos de Nietzsche e defende que também as noções de "eterno retorno do mesmo" e "vontade de potência" possuem uma função crítica provocativa. O cerne da retomada de Nietzsche por Saar está na explicitação de três pressupostos filosóficos assumidos implicitamente pelo projeto genealógico nietzschiano que, segundo o autor, também estão na base de sua empreitada. De acordo com ele, a genealogia nietzschiana é, em primeiro lugar, uma história do eu, e oferece uma noção de subjetividade distinta daquelas defendidas pela filosofia do sujeito. Em segundo lugar, ela é uma história da relação entre subjetividade e poder. Por fim, a genealogia constitui uma forma particular de narrativa, que utiliza a retórica para atingir seus fins. Para Saar, é lançando mão desses três elementos que Nietzsche faz com que a história se transforme em crítica.

Se, na primeira parte do livro, Saar explicita alguns dos principais elementos do modelo genealógico de crítica, é apenas a partir de sua junção com outros elementos, extraídos da obra de Foucault, que ele irá pensá-la como crítica social. Com o objetivo de mostrar como a crítica genealógica funciona como crítica social e, mais do que isso, como ela pode desencadear transformações práticas, Saar dedica então a segunda parte do livro a Foucault. Ali, Saar recusa a tese de que os escritos tardios de Foucault representam uma negação da teoria do poder apresen- 
tada por ele anteriormente e procura ressaltar alguns elementos de sua obra que seriam centrais àqueles que querem, como ele, desenvolver uma crítica genealógica. Dentre estes, dois nos são particularmente importantes. O primeiro consiste na defesa de que a crítica genealógica deve estar pautada por documentos históricos e depoimentos (ainda que a retórica permaneça central) e trata sempre de objetos específicos. O segundo, por sua vez, encontra-se vinculado a sua interpretação dos escritos tardios de Foucault. De acordo com Saar, nesses textos, Foucault visa criticar a forma moderna de subjetividade contrastando-a com a antiga. Ao fazer isso, afirma ele, Foucault sublinha o potencial crítico-transformador da genealogia, que poderia levar à abertura do campo ativo de ação para o sujeito.

No sétimo capítulo do livro, por fim, Saar combina os elementos reconstruídos por ele até então e ressalta o potencial crítico da genealogia. Ele defende que a crítica genealógica é uma forma de crítica imanente, na medida em que se inscreve na práxis da rejeição daquilo que é válido no presente, e afirma que, apesar de partir da pressuposição de que o poder moldou o eu, ela também põe o eu, enquanto leitor, como seu ponto de chegada. A dramatização das relações de poder empreendida pela genealogia funcionaria como uma provocação que pode levar o sujeito a uma autocrítica ativa. A crítica genealógica não seria, portanto, nem cínica nem utópica; ela não postularia nem a absolutização do poder, nem a da liberdade.

Se Saar encontra, nessa abordagem, uma saída para a dificuldade de se pensar a crítica sem lançar mão de um dualismo, outros autores, como Rahel Jaeggi, não demoraram para identificar, nela, outras dificuldades. Contrapondo-se ao projeto genealógico, Jaeggi afirma que "toda forma de compreender o mundo 
é perspectiva, 'construída' e produz normas, pois não pode haver uma realidade (social) sem que o campo da interpretação e da possibilidade seja determinado. Mostrar isso, contudo, não é criticar. Simplesmente observar que o existente é 'construído', aberto a questões e modificável não gera um critério que permita decidir se e por que determinadas instituições ou determinadas compreensões da realidade social estão erradas e devem, portanto, ser modificadas" (Jaeggi, 2009b, pp. 281-282). Para ela, a defesa de Saar de que todas as práticas estão perpassadas pelo poder acaba igualando-as e impedindo a formulação de um critério normativo para sua avaliação.

Apesar de rejeitar, como Saar, a tese da colonização do mundo da vida e se subscrever ao programa honnethiano de desenvolver um modelo monista de crítica social, Jaeggi procura realizá-lo de outro modo. Assumindo que a dominação não pode ser compreendida sem que se atente para seu caráter normativo, a autora procura fazer uma crítica das instituições sociais que, diferentemente daquela desenvolvida por Saar, esteja apta a diferenciar "instituições mais ou menos consolidadas, instituições melhores ou piores e possa, assim, dar conta do próprio sentido e da arbitrariedade de processos sociais complexos, sem deixar como um todo os fundamentos da teoria da ação" (Jaeggi, 2009a, p. 544). Trata-se de fazer uma crítica das instituições que atente para suas diferenças no que diz respeito à promoção ou ao bloqueio da liberdade, sem que isso signifique lançar mão de um dualismo.

De acordo com Jaeggi, apesar de ter sido praticamente abandonado pela academia, o conceito de alienação é hoje o mais adequado para essa tarefa. Reabilitá-lo, contudo, não é uma tarefa fácil. Para tanto, a autora terá primeiro de mostrar que 
é possível desvinculá-lo de concepções metafísicas de natureza humana ou de vida boa, às quais ele foi comumente vinculado. Na primeira parte do livro, ela recusa noções de vida não alienada que postulam uma unidade prévia entre sujeito e objeto ou entre o trabalhador e o fruto do seu trabalho, como critério para a crítica. A alienação, afirma ela, deve ser entendida de modo mais formal, como o resultado de um processo falho de apropriação, que ocorre sempre que o sujeito se encontra impossibilitado de tomar o mundo social e sua própria vida como resultado de suas ações. Retomando autores clássicos da filosofia "continental", assim como autores da tradição analítica de filosofia, Jaeggi procura desenvolver um conceito mais formal de alienação que, atento ao processo de formação da identidade e não ao seu conteúdo, não assuma pressupostos metafísicos.

Ao fazer isso, a autora procura dar conta das diferentes utilizações da noção de alienação no discurso cotidiano e dos fenômenos de alienação nas sociedades capitalistas atuais, que vão desde o estabelecimento de uma relação estratégica do sujeito frente aos outros e ao mundo, até a realização de tarefas com as quais ele não se identifica, passando por situações de conformismo social, quando eles representam papéis sociais nos quais não se reconhecem, e por uma perda de relação com o contexto social em que vivem. Nas duas primeiras partes do livro, a autora mostra então que os fenômenos da alienação podem ser entendidos como o resultado de uma falha nesse processo de apropriação. Na terceira, por sua vez, ela passa a enfatizar como a liberdade dos sujeitos depende do sucesso deste mesmo processo. Com isso, ela aponta não só para a pertinência do conceito de alienação para um diagnóstico das patologias sociais, como para o vínculo entre sua superação e a emancipação. 
Embora os fenômenos explorados pela autora tenham como foco a autoalienação, em que o sujeito alienado é, ao mesmo tempo, vítima e autor, Jaeggi procura se afastar da vertente conservadora da alienação, atribuída por ela a Heidegger e Kierkgaard, para a qual a alienação resultaria da própria passividade dos sujeitos. Seguindo, nesse aspecto, a tradição marxista e hegeliana da crítica da alienação, Jaeggi afirma que é preciso atentar para as causas sociais desses fenômenos patológicos, isto é, para as instituições sociais que impedem o indivíduo de se reconhecer como autor de sua própria vida e do mundo em que vive. Tomando o sucesso desse processo de apropriação como critério, Jaeggi critica as instituições sociais que o impedem. Com isso, a autora pode condenar determinadas instituições, como a economia capitalista e as estruturas sexistas e racistas de valor, que se impõem aos sujeitos como algo natural e não passível de alteração.

Ao lançar mão do conceito de alienação, Jaeggi desenvolve um modelo de teoria crítica que procura entender os fenômenos ideológicos presentes nas sociedades capitalistas atuais, bem como criticá-los, explicitando o seu caráter normativo e denunciando, com isso, o fato de que eles bloqueiam sua própria contestação. Embora compreenda sua crítica das instituições como uma crítica da ideologia, já que seu objetivo é denunciar uma falsa consciência socialmente necessária à manutenção do status quo, Jaeggi não defende que os sujeitos se encontram estruturalmente presos a uma falsa consciência. Para ela, a alienação gera crises e, ao fazê-lo, abre espaço para sua própria crítica e superação prática.

Apesar de compartilhar com Jaeggi o diagnóstico de que a principal tarefa de uma teoria social crítica hoje é a de criticar 
normas e instituições sociais ideológicas que geram ou mantêm relações de dominação, Celikates não acredita que ela possa ser realizada por meio de uma crítica genealógica ou de uma crítica tradicional da ideologia, tal como eles. Embora afirme que não podemos negar que "sob condições de um não reconhecimento institucionalizado e estrutural, os atores são impedidos de desenvolver ou exercitar as suas capacidades reflexivas", Celikates ressalta que não se deve perder de vista que "para ser fiel ao seu intuito emancipatório, a teoria crítica tem de evitar a 'armadilha da incapacitação', isto é, o perigo de restringir ainda mais as capacidades dos atores através de seu diagnóstico" (Celikates, 2009, p. 41). Para ele, a teoria não pode prescindir de um critério normativo, nem partir de um diagnóstico segundo o qual as pessoas, cegadas por uma falsa consciência necessária, sejam tomadas como incapazes de se distanciar do contexto social em que vivem e, portanto, de criticá-lo.

Em Crítica como práxis social, Celikates defende um tipo de crítica reconstrutiva que, análogo à psicologia, possibilitaria uma crítica imanente das patologias sociais que impedem que os próprios concernidos se deem conta das relações de dominação às quais estão submetidos, sem aceitar, com isso, o diagnóstico da incapacitação dos atores sociais ou o da absolutização do poder. Assumindo que, em muitos contextos sociais, as condições necessárias para que os próprios concernidos possam exercer suas capacidades reflexivas não estão dadas, Celikates sustenta que a principal tarefa da teoria crítica é criticá-los. Tendo em vista a efetivação das condições sociais necessárias à reflexividade e, portanto, a da própria crítica social, ele se debruça então sobre dois diferentes tipos de sociologia, reconstruídos a partir dos trabalhos de Bourdieu e Boltanski, para apresentar, ao final, sua 
própria concepção de crítica social. Por meio dela, Celikates procura combinar os insights dos dois autores sem recair nos problemas que identifica em suas teorias.

Após uma breve introdução, na qual apresenta os contornos gerais de sua tese, Celikates dedica o primeiro capítulo do livro ao que chama de "modelo da ruptura" que, ao assumir que há uma diferença epistemológica entre o ponto de vista dos teóricos e o dos participantes, defende que apenas os primeiros seriam capazes de se distanciar e criticar o mundo social em que vivem. Voltado a uma análise das estruturas sociais que impedem os sujeitos de tomarem consciência de sua própria condição, esse modelo crítico - analisado por Celikates principalmente a partir da sociologia crítica de Bourdieu - assume que só podemos fazer uma análise objetiva da sociedade quando nos afastamos da perspectiva do participante. Para os defensores dessa forma de sociologia crítica, a capacidade de se distanciar criticamente é uma prerrogativa do cientista social, motivo pelo qual caberia apenas a ele a tarefa de analisar objetivamente a sociedade e explicitar aquilo que os próprios sujeitos sociais jamais teriam como perceber sozinhos.

Segundo Celikates, ao se distanciar de uma critica interna, esse modelo ressalta como, muitas vezes, os próprios atores sociais aceitam normas e valores que não poderiam reflexivamente aceitar. Contudo, ao negar que o poder e a dominação possam ser questionados a partir da própria práxis social, bem como que os participantes possuam uma capacidade reflexiva, a crítica externa acaba também pondo em questão suas própria bases normativas e recusa a possibilidade de transformações sociais emancipatórias. Além disso, afirma Celikates, essa forma de crítica falseia a realidade social. Ao enfatizar os bloqueios e as 
estruturas sociais que impedem a reflexão, ela exclui sistematicamente de seu diagnóstico as práticas de reflexão e justificação existentes.

Tendo em vista essas e outras dificuldades, Celikates dedica o segundo capítulo do livro ao trabalho de Boltanski que, apesar de ter sido aluno de Bourdieu, recusa sua sociologia crítica e desenvolve uma teoria social cujo foco está na reconstrução das práxis sociais de crítica e justificação. Diferentemente de Bourdieu, a sociologia da crítica desenvolvida por Boltanski, toma a práxis social da crítica como ponto de partida e mostra, com base nela, que a ruptura epistemológica pressuposta pela sociologia crítica está socialmente equivocada. Para tanto, Boltanski tira o foco das estruturas sociais ou de outras forças que atuam pelas costas dos atores, colocando-o nas complexas práticas de justificação e de crítica, bem como na compreensão que os atores têm delas. Ao mostrar que as pessoas estão ocupadas em se explicar, descrever e justificar suas ações aos demais, a sociologia da crítica sustenta que a reflexividade corresponde a uma característica não espetacular da ação social. Seu ponto de partida é, portanto, a simetria e não a ruptura entre a perspectiva dos teóricos e a dos atores sociais.

A sociologia da crítica explicita a práxis pré-científica sobre a qual a crítica e a transformação social se ancoram. Porém, na medida em que enfatiza apenas essas práticas reflexivas, ela parece relegar a um segundo plano a discussão acerca das condições sociais necessárias ao pleno desenvolvimento das capacidades reflexivas dos atores sociais. Para Celikates, Boltanski parece considerar que o desenvolvimento das capacidades reflexivas se apoia no ar e não em determinadas condições sociais. Por esse motivo ele se pergunta, afastando-se de qualquer teoria 
que assuma acriticamente do ponto de vista dos participantes, se é mesmo possível supor que tais capacidades estão sempre dadas ou se, pelo contrário, há situações em que elas se encontram limitadas ou bloqueadas devido à ausência das condições sociais necessárias ao seu desenvolvimento.

Apesar de recusar o modelo da ruptura, Celikates defende que a crítica depende da efetivação de certas condições sociais. Segundo ele, as estruturas sociais retratadas por Bourdieu podem bloquear ou limitar o desenvolvimento das capacidades reflexivas dos agentes sociais. Ainda que hoje, devido à heterogeneidade de práticas sociais, uma ideologia nunca seja total ou socialmente necessária, ela pode ser efetiva e limitar a capacidade dos concernidos de criticá-la. Para Celikates, portanto, não é possível negar que, muitas vezes, as pessoas aceitam a imagem depreciativa que os outros fazem delas e percebem a si mesmas pelos olhos dos outros. No entanto, a existência de tais autoimagens depreciativas e ideológicas também não faz com que ele recuse o ponto de vista dos participantes como estruturalmente irrefletido. Essa tensão, que seria inerente à teoria crítica, o leva a defender uma noção de crítica reconstrutiva que, análoga à psicanálise, conseguiria superar os problemas ligados à crítica social externa sem assumir a posição ingênua que caracteriza as teorias que partem diretamente de uma crítica interna.

No último capítulo do livro, Celikates distingue três tipos de crítica reconstrutiva e defende, dentre eles, aquele desenvolvido por Habermas em Conhecimento em Interesse. De acordo com ele, enquanto as reconstruções ligadas à pragmática formal e ao hegelianismo de esquerda estão preocupadas com a explicitação de uma estrutura social normativa, o tipo de reconstrução defendido por ele parte da análise de patologias sociais concretas. 
Com pretensões mais modestas, essa forma de crítica parte de um diálogo entre teóricos e participantes para elaborar uma análise de instituições, normas e valores patológicos que impedem o pleno desenvolvimento das capacidades reflexivas dos atores sociais. Tendo como foco situações específicas, essa forma dialógica de crítica explicitaria como determinadas imagens de mundo são reflexivamente inaceitáveis para os concernidos e, com isso, mostra que elas se mantiveram apenas por meio da coerção (Celikates, 2009, p. 217). A limitação das capacidades reflexivas dos atores é, assim, diagnosticada e trazida para um diálogo entre os teóricos críticos e os atores sociais, que pode destravar o potencial emancipatório inscrito na própria práxis social. A crítica pode, desse modo, desencadear, de forma análoga à da psicanálise $^{1}$, o distanciamento crítico dos próprios concernidos frente ao contexto social em que vivem e possui, nesse sentido, um papel eminentemente prático (Celikates, 2009, p. 189).

Embora aponte para a importante tensão entre crítica interna e externa, que perpassa a teoria crítica, e desenvolva uma interessante concepção de crítica social, o modelo de Celikates, como os de Saar e Jaeggi, pode ser problematizado. Ao defender uma relação entre teoria e práxis na qual o teórico assume um papel prático, por exemplo, Celikates pode ser acusado de romper o vínculo entre teoria e práxis que procura fortalecer. Ao discutirmos os livros desses três autores, nosso principal objetivo contudo não foi problematizá-los, mas indicar aquilo que eles apresentam de novo e produtivo no interior do cenário atual de discussão. Afinal, além de serem os principais proponentes de

\footnotetext{
${ }^{1}$ Ao contrário da psicanálise, contudo, a teoria crítica tem como foco apenas os impedimentos sociais - e não impedimentos internos ou psicológicos à reflexão (Cf. Celikates, 2009, pp. 199-200).
} 
uma nova geração de teóricos críticos, Saar, Jaeggi e Celikates também parecem representar o início de um novo momento na teoria crítica. Enquanto Habermas e Honneth parecem ter centrado seus esforços na reconstrução da estrutura normativa da interação social, eles deslocam seus esforços para a elaboração de uma crítica situada em cujo centro está a preocupação com as patologias que perpassam a interação social. Tanto Celikates, como Jaeggi e Saar defendem que o foco da teoria crítica deve estar na crítica das normas, valores e instituições sociais que possuem um caráter ideológico. Mais do que isso, todos eles concordam com a exigência de que a crítica parta de casos concretos, isto é, de uma análise da instituição, da norma ou do valor que visa criticar.

Ainda que divirjam radicalmente quanto ao tipo de análise que cabe ao teórico crítico fazer ou mesmo quanto às características dos valores ideológicos criticados, todos eles concordam no que diz respeito ao caráter específico da crítica, bem como que ela deve estar focada em instituições sociais. Este projeto comum norteia o trabalho desses autores, que se encontra ainda em estágio de formulação. Seus primeiros passos já foram dados, mas até esse momento, é preciso reconhecer, que nenhum deles desenvolveu um modelo crítico capaz de competir em complexidade e abrangência com aqueles que são criticados por eles. Longe de representar um problema, esse fato constitui apenas mais um motivo para que aqueles que nutrem interesse pela teoria crítica continuem atentos a suas publicações.

\section{Referências bibliográficas}

CELIKATES, R. Kritik als soziale Praxis. Gesellschaftiliche Selbstverständigung und kritische Theorie. Frankfurt am Main: 
Campus Verlag, 2009.

"O não reconhecimento sistemático e a prática da crítica: Bourdieu, Boltanski e a prática da teoria crítica". Novos Estudos - CEBRAP, n. 93, jul. 2012, pp. 28-42.

FRASER, N. "Distorted Beyond All Recognition: A Rejoinder to Axel Honneth". In: Redistribution or Recognition? A Political-Philosophical Exchange. New York London: Verso, 2003.

HABERMAS, J. Erkenntinis und Interesse. Frankfurt am Main: Suhrkamp, 1968.

. Theorie des Kommunicativen Handelns. Band II. Frankfurt am Main: Suhrkamp, 1987.

HONNETH, A. Kritik der Macht. Reflexionsstufen einer kritschen Gesellschaftstheorie. Frankfurt am Main: Suhrkamp, 1989 .

- Luta por Reconhecimento. A gramática moral dos conflitos sociais. São Paulo: Editora 34, 2003.

"Einleitung: Genealogie als Kritik". In: HONNETH, A.; SAAR, M. (orgs.) Michel Foucault. Zwischenbilanz einer Rezeption. Frakfurter Foucault-Konferenz 2001. Frankfurt am Main: Suhrkamp, 2003, pp. 117-121.

- Verdinglichung. Eine Anerkennungstheorethische Studie.

Frankfurt am Main: Suhrkamp, 2005.

HONNETH, A.; HARTMANN, M. "Paradoxien der kapitalistischen Modernisierung. Ein Untersuchungsprogramm". In: HONNETH, A. Das Ich im Wir. Studien zur Anerkennungstheorie. Frankfurt am Main: Suhrkamp, 2010, pp. 222-249.

11. JAEGGI, R. Entfrendumg. Die Aktualität eines sozialphilosophischen Problems. Frankfurt am Main: Campus Verlag, 2005. 
"Was ist eine (gute) Instituition?". In: JAEGGI, R.; FORST, R.; HARTMANN, M.; SAAR, M. (orgs.) Sozialphilosophie und Kritik. Frankfurt am Main: Suhrkamp, 2009, pp. 528-44.

. "Was ist Ideologiekritik". In: WESCHE, T; JAEGGI, R. Was ist Kritik?. Frankfurt am Main: Surhkamp, 2009, pp. 266-295.

NOBRE, M. "Teoria Crítica: uma nova geração". Novos estudos - CEBRAP, n. 93, jul. 2012, pp. 23-27.

OWEN, D.; VAN DEN BRINK, B. (orgs) Recognition and Power. Axel Honneth and the Tradition of Critical Social Theory. Cambridge: Cambridge University Press, 2007.

PATHERBRIDGE, D. The Critical Theory of Axel Honneth. Lahan: Lexington Books, 2013.

SAAR, M. Kritik als Genealogie. Geschichte und Theorie des Subjekts nach Nietzsche und Foucault. Frankfurt am Main: Campus Verlag, 2005.

"Genealogische Kritik". In: JAEEGI, R.; WESCHE, T. Was ist Kritik?. Frankfurt am Main: Suhrkamp, 2009, pp. 247-265.

"Macht und Kritik". In: JAEGGI, R.; FORST, R.; HARTMANN, M.; SAAR, M. (orgs,) Sozialphilosophie und Kritik. Frankfurt am Main: Suhrkamp, 2009, pp. 567-587. WESCHE, T; JAEGGI, R. Was ist Kritik?. Frankfurt am Main: Surhkamp, 2009. 
